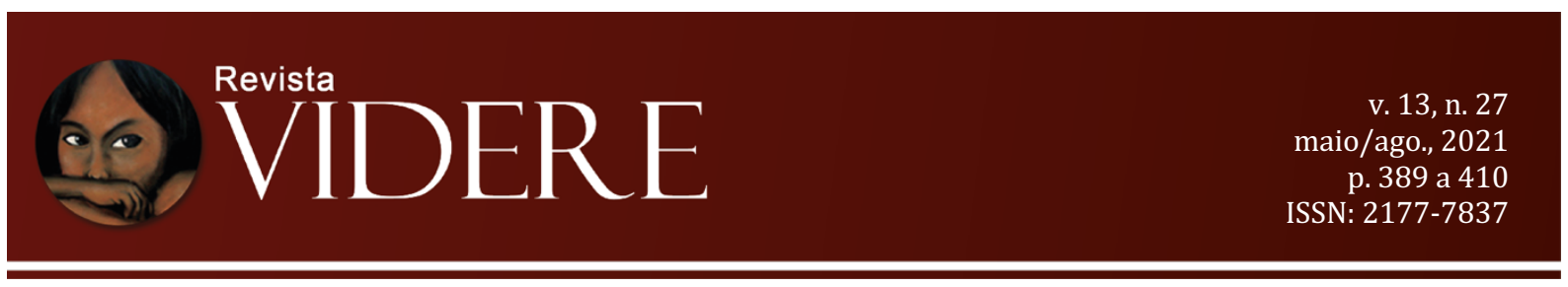

\title{
NARRATIVIDADE E O DIREITO À DIFERENÇA: A ALTERIDADE COMO PROPOSTA DE SUPERAÇÃO DA EXCLUSÃO
}

\author{
NARRATIVITY AND THE RIGHT OF DIFFERENCE: THE OTHERNESS AS A \\ PROPOSAL OF OVERCOME EXCLUSION
}

\author{
NARRATIVIDAD Y DERECHO A LA DIFERENCIA: LA ALTERIDAD COMO \\ PROPUESTA PARA SUPERAR LA EXCLUSIÓN
}

\author{
Maria Carolina Braz da Silva Azevedo \\ Doutoranda em Direito (UFPA) \\ Universidade Federal do Pará \\ carolbrazsa@gmail.com \\ OrcidID: https://orcid.org/0000-0003-2661-4185 \\ Ricardo Evandro Santos Martins \\ Doutor em Direito (UFPA) \\ ricardoevandromartins@gmail.com \\ OrcidID: https://orcid.org/0000-0001-8648-1260
}

\begin{abstract}
Resumo: Nesse artigo, tivemos o intuito de elaborar uma proposta de superação da realidade de exclusão de determinadas subjetividades e, para isso, iniciamos definindo a subjetividade a partir de sua relação com a linguagem. Em seguida, partimos para a investigação sobre como as limitações da possibilidade de formulação linguísticas e da participação em práticas discursivas funcionam como modelos de normalização colonizadora que determinam as possibilidades de expressão das subjetividades e do surgimento de subjetividades distintas. Por fim, por meio do método hipotético-dedutivo e considerando a alteridade como uma prática que preza pela ética do respeito, da solidariedade e da abertura para o Outro como subjetividade distinta, apontamos essa hipótese como um meio possível de superação da racionalidade de exclusão para além de um simples reconhecimento do Outro, mas sobretudo a partir da responsabilidade com o Outro em um movimento de ruptura com a racionalidade moderna que sustenta aquelas relações de exclusão.
\end{abstract}

Palavras-chave: Subjetividade. narratividade. direito à diferença. racionalidade moderna. alteridade.

Abstract: In this article, we aimed to develop a proposal to overcome the reality of excluding certain subjectivities and, for this, we started by defining the subjectivity based in its 
relationship with language. Then, we set out to investigate how the limitations of the possibility of linguistic formulation and participation in discursive practices serve as models of colonizing normalization that determine the possibility of expressing subjectivities and the emergence of diferente subjectivities. In the end, using the hypothetical-deductive method and considering otherness as a practice that values the ethics of respect, solidarity and openess to the Other as a different subjectivity, we pointed out this hypothesis as a possible way of overcoming the rationality of exclusion beyond a simple recognition of the Other, but above all from the responsability with the Other in a moviment of rupture with the modern rationality that sustains those exclusion relations.

Key-words: Subjectivity. narrativity. right to difference. modern rationality. otherness.

Resumen: En este artículo, tuvimos la intención de elaborar una propuesta para superar la realidad de exclusión de determinadas subjetividades y, para ello, comenzamos por definir la subjetividad a partir de su relación con el lenguaje. Luego, comenzamos a investigar cómo las limitaciones de la posibilidad de formulación lingüística y participación en prácticas discursivas funcionan como modelos de normalización colonizadores que determinan las posibilidades de expresión de subjetividades y el surgimiento de subjetividades distintas. Finalmente, a través del método hipotético-deductivo y considerando la alteridad como una práctica que valora la ética del respeto, la solidaridad y la apertura al Otro como una subjetividad distinta, señalamos esta hipótesis como un posible medio de superación de la racionalidad de la exclusión para más allá de un simple reconocimiento del Otro, pero sobre todo desde la responsabilidad hacia el Otro en un movimiento de ruptura con la racionalidad moderna que sostiene esas relaciones de exclusión.

Palabras clave: Subjetividade. narratividad. derecho a la diferencia. racionalidad moderna. alteridad.

\section{Introdução}

A Modernidade é marcada por uma racionalidade voltada para o sujeito individualmente considerado, colocando-o como foco do seu pensamento ao tratar de sua racionalidade e autonomia. Também, ensejou a imposição de valores e normas como universais. A pós-modernidade, por sua vez, ao tentar superar as metanarrativas modernas, acabou por intensificar o pensamento individualista, negando a possibilidade de obtenção de um consenso coletivo, negando os valores e normas diferentes daqueles padrões universais.

Diante dessa racionalidade, surge o debate acerca da identidade e da diferença, aprofundando-se em uma discussão sobre o surgimento e a normalização de (novas) subjetividades. Primeiramente iremos estabelecer uma distinção entre os conceitos de identidade e subjetividade. A seguir, iremos demonstrar como o surgimento da identidade e da diferença estão intimamente relacionados, mantendo uma tensão constante. 
Na seção seguinte, com fundamento na hermenêutica da linguagem de Hans-Georg Gadamer, iremos relacionar a forma de expressão dessas subjetividades com o seu caráter eminentemente linguístico, demonstrando como a constituição dessas subjetividades se dá por meio da linguagem e, em seguida, como as práticas discursivas (linguísticas) restringem, interditam e normalizam essas subjetividades, tomando como referencial a hermenêutica da suspeita, principalmente, Michel Foucault.

Por fim, iremos discutir a partir das noções de alteridade proposta por Emmanuel Levinas, de forma conjunta com a Filosofia da Libertação de Enrique Dussel, uma proposição para a superação dessa racionalidade que fundamenta as relações de poder que determinam a prática discursiva, a fim de viabilizar a participação política das subjetividades distintas a partir do seu empoderamento, da sua própria voz.

\section{Considerações iniciais sobre identidade e diferença}

A luta diária pela sobrevivência vivida pelo cidadão comum, o retira de qualquer tipo de envolvimento e preocupação com instituições, valores, princípios e com a coletividade. Enfraquecendo movimentos sociais, instâncias coletivas de lutas e mergulhando-o em um profundo narcisismo.

Durante a Modernidade foi construída uma racionalidade voltada ao sujeito, ao homem, o indivíduo possuía a centralidade nos contextos sociais, havia o desenvolvimento do foco na racionalidade e na autonomia desse sujeito. Este pensamento respaldou a imposição de crenças, normas e valores de um determinado grupo social hegemônico, dominante naquele contexto, como se fossem autenticamente absolutos e universais (Olivé, 2006, p. 84) O pensamento pós-moderno, por sua vez, ao tentar esvaziar as metanarrativas oriundas da modernidade, deu ênfase a essa perspectiva individualista, favorecendo uma visão liberal, sistêmica e hegemônica, negando a possibilidade de "um consenso articulador das diferenças ou resistências localizadas em torno de um projeto coletivo" (Freitas, 2005, p. 55), desarticulando movimentos sociais e dificultando sua organização.

Essa ênfase no específico retirou a referência coletiva das sociedades, antes articulados em torno da genericidade humana em relação dialética com a noção de indivíduo, agora, após o rompimento dessa relação, os indivíduos estão à mercê de sua finitude, restritos a seu próprio eu, lutando pela sua vida imediata e fragmentária. O pós-modernismo, portanto, em verdade, é uma negação da modernidade técnica em nome da modernidade da libertação (WALLERSTEIN, 2002, p. 150). Segundo, Luiz Carlos de Freitas (2005, p. 93), é esse modo 
de enxergar a diferença que leva à fragmentação e à ausência de diálogo i entre os diferentes, a partir dessa situação, o diferente é respeitado, mas rejeitado do meu espaço, devendo as diferenças permanecerem enclausuradas, distanciamento que dificulta o estabelecimento de um consenso, de uma união para os movimentos sociais.

É nesse contexto de exacerbação da noção de individualidade e de constituição das identidades no sistema do capitalismo global que propomos uma discussão acerca das noções de identidade e diferença. Ao esvaziar o humano, a ideia da genericidade, os pós-modernos promovem a indeterminação, combatendo de forma absoluta a ideia de totalidade, de um elemento comum, de unificação do coletivo, pelo que acabam caindo no relativismo radical, em que o interesse circunda apenas questões relacionadas ao indivíduo por si só. Como afirma Kathryn Woodward (2014, p. 21), a globalização "produz diferentes resultados em termos de identidade. A homogeneidade cultural promovida pelo mercado global pode levar ao distanciamento da identidade relativamente à comunidade e à cultura local”.

No ensejo desta discussão, é necessário esclarecer o significado dos termos "subjetividade" e "identidade". Kathryn Woodward afirma que os termos "subjetividade" e "identidade" geralmente são utilizado de forma intercambiável, como se tivessem o mesmo sentido, o que não é verdade. Subjetividade é a compreensão que temos sobre o nosso eu, envolve os pensamento e as emoções conscientes e inconscientes que constituem nossa compreensão sobre quem nós somos, ou seja, os pensamentos e emoções mais pessoais. Todavia, essa subjetividade é vivida "em um contexto social no qual a linguagem e a cultura dão significado à experiência que temos de nós mesmos e no qual nós adotamos uma identidade" (2014, p. 56). Assim, as subjetividades são sujeitas ao discurso, os próprios sujeitos se posicionam de um modo perante os discurso, são sujeitados a ele, constituindo uma identidade.

As referidas identidades somente adquirem sentido por meio da linguagem, dos sistemas simbólicos a partir dos quais elas são representadas. Segundo aquela mesma autora, a identidade é constituída pela diferença, define-se quem se é a partir da diferença em relação ao outro, àquilo que não é, bem como a diferença é sustentada pela exclusão, se você é a, não pode ser b. Tais diferenças são vistas como mais ou menos importantes que outras conforme os lugares e contextos históricos. Ou seja, a diferença de identidades é histórica.

Desse modo, identidade e diferença são interdependentes, partilhando a característica comum de serem resultado de uma produção linguística, o que "significa dizer que não são 'elementos' da natureza, que não são essências, que não são coisas que estejam simplesmente aí, à espera de serem reveladas ou descobertas, respeitadas ou toleradas. A identidade e a 
diferença têm que ser ativamente produzidas" (Woodward, 2014, p. 76), ou seja, elas são produto social e cultural. Essa criação se dá por meio de atos de linguagem e esta é fundamentalmente um sistema de diferenças, os signos linguísticos só adquirem sentido quando interpretados dentro de um contexto, dentro do sistema linguístico.

Assim, elas não podem ser compreendidas fora desse sistema linguístico que lhes dá significado. Essa estrutura linguística varia conforme o contexto histórico, ela não é fixa, determinada, também por isso as noções de identidade e diferença variam. Esse sistema de signos linguísticos, para além de expressar aquilo que é (identidade), também apresenta traços daquilo que não é (diferença). Portanto, identidade e diferença são definidas a partir das práticas discursivas (linguísticas), razão pela qual estão sujeitas às relações de poder, ou seja, identidade e diferença não surgem a partir de uma relação harmoniosa, de uma simples definição daquilo que é e daquilo que não é, mas sim surgem de conflitos, de lutas pelo poder, pela produção do discurso.

Entendemos que a discussão sobre a diferença é importante não em si mesma, isolada, como o fazem os pós-modernos quando a absolutizam, impedindo o seu movimento, a sua dinamicidade. Para nós ela é importante enquanto permite a contradição, estabelecendo diálogo com o outro com uma perspectiva de superação, ou seja, a diferença é relevante somente enquanto permite, diante do enfrentamento com o outro, a realização do diálogo. A particularidade do sujeito, por sua vez, surge na relação entre a unidade, o identitário, aquilo que é comum a determinado grupo conforme atribuições sociais, e o diferente, a diversidade, a sua distinção, “o indivíduo é produto dessa dialética que resulta na sua particularidade” (Freitas, 2005, p. 79).

Sobre o papel dos coletivos, da genericidade, na constituição da identidade pessoal, o autor León Olivé (p. 88) afirma que ele se dá a partir da identificação de práticas, costumes, valores e normas comuns àquele grupo, sendo estes os elementos que dão a ele unidade e força para a prática de movimentos sociais de resistência à hegemonia. Como afirma Joan Scott (2005, p. 12), a tensão entre identidade pessoal (direitos individuais) e identidade do grupo é sempre existente e mesmo deve ser mantida, tendo em vista que ela nos permite buscar resultados melhores e mais democráticos.

Portanto, nessa perspectiva da diferença como sendo dialogada, estabelecendo uma dialética entre a genericidade e a individualidade, compreendemos que o ser humano é um ser coletivo, só se realiza em contato com a sua genericidade, o que, entretanto, não nega as particularidade e necessidades das lutas locais, mas sim, serve para dar ênfase à noção de que a prática dessas lutas de forma isolada, fragmentária, retira delas a força decorrente de 
elementos comuns que geram um apoio mais amplo, enfraquecendo a própria resistência (Freitas, 2005, p. 95-96). É preciso, assim, associar questões da genericidade humana a questões das particularidades locais, em razão de que, por si só, "a noção de igualdade faz sombra à possibilidade de um reconhecimento da singularidade ou particularidade de cada qual" (Bittar, 2009, p. 552).

\section{Linguagem, narratividade e subjetividade}

Na seção anterior apresentamos de forma breve como a linguagem é constitutiva da subjetividade. Nesta seção, iremos nos aprofundar primeiramente sobre qual a noção de linguagem que escolhemos como fundamento da pesquisa para, a partir disso demonstrar como essa linguagem está inserida em uma rede de relações de poder que determinam quem pode se expressar formulando discursos e qual conteúdo dos discursos será considerado válido e legítimo. Para finalizar esta seção, iremos discutir de que modo as práticas discursivas influenciam na normalização das subjetividades.

O pensamento de Hans Georg Gadamer representou um giro radical (giro hermenêutico) em oposição à busca pela verdade a partir de métodos racionais, tendo como ponto de partida uma filosofia da linguagem como a morada do ser e o espaço de desvelamento da tradição.

A articulação do conceito filosófico de verdade como produto de uma tradição histórica aproximou Gadamer de uma releitura crítica do conceito de pré-juízo [Vorurteil], também traduzido como preconceito, a construção da historicidade em Gadamer mostra que todo conhecimento é forjado necessariamente a partir de pré-juízos, isto é, de significados construídos historicamente que são como que a ferramenta a partir da qual qualquer novo conhecimento pode ser construído.

Tais concepções prévias são adquiridas pelas vivências do intérprete, tudo aquilo que ele experienciou constitui um significado para as coisas do mundo, a sua forma de vê-las é précompreensão de si mesmo. Gadamer (2003, p. 12) afirma que

É verdade que os preconceitos que nos dominam frequentemente comprometem o nosso verdadeiro reconhecimento do passo histórico. Mas sem uma prévia compreensão de si, que é neste sentido um preconceito, e sem a disposição para uma autocrítica, que é igualmente fundada na nossa autocompreensão, a compreensão histórica não seria possível nem teria sentido. 
Neste sentido, surge na hermenêutica gadameriana o conceito de horizonte. Este pode ser entendido como a visão de mundo do intérprete constituída por seus preconceitos, é uma visão prévia global construída em diversos contextos anteriores e sob a qual se projeta toda a compreensão futura.

O horizonte é uma abertura limitada, portanto, que muda assim que se muda o ponto de vista de um. Um horizonte de significado, que é uma variação contínua da existência lingüística, é um todo na medida em que pode se dar junto com a infinitude do não-ditoii (tradução nossa) (Figal, 2002, p. 120).

Assim, o conhecimento e a compreensão de determinada tradição constituem a visão de mundo daqueles indivíduos que nela estão inseridos (Gadamer, 2015). Ainda, essa visão de mundo é constantemente mutável em decorrência das experiências vivenciadas por esses indivíduos de forma singular e como membros de um grupo que compartilha a mesma tradição. Nesse sentido, a linguagem representa uma expressão da visão de mundo, da identidade e da forma de vida daquele grupo.

Querer afastar a investigação da tradição histórica em busca de objetividade metódica não aproxima o pesquisador da verdade, mas torna seus resultados mais superficiais, na medida em que deliberadamente busca ignorar os próprios fios que historicamente forjaram aquele pensamento.

É na Terceira Parte de Verdade e Método I que Gadamer trata da questão da linguagem como o momento em que se dá toda a compreensão, sendo possível ocorrer o compreender somente na linguagem. Segundo Josef Bleicher (2002, p. 162) "Para Gadamer, o problema da linguagem constitui o tema central da filosofia hermenêutica". Não existe ponto de vista de interpretação ou visão nenhuma exterior à experiência do mundo da linguagem, "a linguagem na concepção gadameriana não se limita somente a se referir a outra coisa: convida a demorar-se nela. Não é inerente ao que representa, mas sim participa de algum modo nele"iii (tradução nossa) (Arrizabalaga, 2005, p. 250).

"Não existe pensamento sem linguagem" (Grondin, 2012, p. 76), ela compreende todo e qualquer objeto que pode ser compreendido, bem como é uma forma de abertura ao objeto e a outros horizontes linguísticos. A partir dessa afirmação, compreendemos que a linguagem permite uma abertura a outros horizontes linguísticos, o que, em nosso caso, podemos entender como uma abertura ao conhecimento do Outro, a partir da possibilidade que se lhe permite de expressão linguística. A linguagem permite uma abertura para um sem número de experiências, de possibilidades de narrativas e formulações discursivas, é por meio dessa abertura que é 
possível reduzir as restrições às práticas discursivas, a fim de considerar a heterogeneidade da linguagem.

Gadamer entende a existência humana como lançada em uma tradição, forjada em um contexto histórico. Esses elementos são articulados na terceira parte de Verdade e Método como elementos que são acima de tudo linguísticos. Assim, pode-se dizer que a tradição e o contexto histórico formam a experiência de "linguisticidade" [Sprachlichkeit] humana.

A partir da exposição acerca da linguisticidade humana como sendo formada pela tradição e pelo contexto histórico, com o destaque dado à noção da linguagem como possibilidade de representar a identidade e a visão de mundo [Weltanschauung] de um indivíduo, ou mesmo de um grupo (um coletivo) que compartilhe uma tradição, razão pela qual a possibilidade de expressar-se linguisticamente se traduz na própria narratividade da tradição, na expressão da subjetividade, o que possibilita opor-se às narrativas hegemônicas que desconsideram os discursos periféricos como participantes da história, partimos agora a uma análise crítica $^{\mathrm{iv}}$ sobre as consequências derivadas da supressão da narratividade, do discurso linguístico.

Propomos a relação entre hermenêutica da linguagem e hermenêutica da suspeita do mesmo modo que Celso Braida (2015) propõe, tomando tanto a hermenêutica compreensiva quanto a genealogia como procedimentos interpretativos. A primeira compreensiva, analisando a manifestação linguística do outro de forma desinteressada em qualquer tipo de dominação; e, a segunda suspeitosa, tratando da manifestação de sentido como de um sujeito assujeitado, com interesse em dominação. Dessa forma, seria incorporada uma dimensão crítica da operação genealógica à hermenêutica filosófica, com a intenção de demonstrar que para além daquilo que é dado pela linguagem, há também o que não é dado e que esconde um sentido.

Inicialmente, destacamos que nossa proposição é do reconhecimento da heterogeneidade dos jogos de linguagem e da aceitação de que o consenso deve ser local, tendo em consideração determinada tradição e contexto histórico, assim, a diferença entre os jogos de linguagem é revolucionária, é o obstáculo contra o qual se chocam as perspectiva de hegemonia de determinados discursos. Para isso, ressaltamos que "não existe 'a linguagem' e não existe 'o ser', mas apenas há acontecimentos que ocorrem”. (Freitas, 2005, p. 9)

Em razão disso, podemos entender que não há discursos universais, capazes de incluir a todos aqueles indivíduos pertencentes à genericidade humana, é preciso considerar em situação de igualdade os discursos distintos, oriundos de diferentes regiões e grupos, como igualmente válidos e legítimos, inclusive os oriundos de linguagens distintas. Foucault nos desaconselha a crer na existência de universais antropológicos, de que há uma verdade sobre o 
humano comum a todas as culturas e a todos os contextos históricos, afirmando que ao criar normas que devem se aplicar a todos os humanos, criamos uma norma a partir da qual os indivíduos poderão ser medidos e julgados.

Por isso, uma genealogia não deve se valer de constantes, deve, pelo contrário, adotar um ceticismo em relação aos universais antropológicos, interrogando-os em sua constituição histórica, "o discurso é um relacionamento complexo e esse relacionamento define as próprias regras de exercício ou de existência da enunciação e dos enunciados.” (Cordeiro, 1995, p. 2) Isso não significa que a universalidade seja problemática e violenta a priori, ela não o é, embora haja circunstâncias em que acarrete violência, em razão de sua indiferença com condições sociais distintas.

Assim, pretendemos apontar que as linguagens e os discursos revelam não somente aquilo que foi dito, o que é evidente e expresso, mas também tudo aquilo que é ocultado no processo de produção de discursos, as tensões e as lutas pela hegemonia nessa relação de poder. Neste ponto reside o papel da filosofia como aquela que mostra "como as coisas que consideramos óbvias e necessárias emergiram de fato de uma rede de práticas humanas contingentes" (Oksala, 2011, p. 16), momento em que notamos a função da investigação histórica sobre como essas práticas foram constituídas.

Michel Foucault afirma que em toda a sociedade a produção do discurso é de certa forma controlada, selecionada e organizada em um certo número de procedimentos que lhe conferem poderes. Tais procedimentos podem acarretar a exclusão que pode ser exercida por meio da interdição. Esta é a limitação daquilo que se pode dizer e de quem pode dizer, havendo um direito privilegiado ou exclusivo do sujeito que fala, que tem legitimidade para proferir discursos (Foucault, 1999).

Seguindo a ideia do autor de que o poder não é apenas limitador, autoritário, restritivo, mas também produtivo, incitando formas de experiência e conhecimento, ao invés de apenas reprimi-las e censurá-las, a autora Johanna Oksala (2011, p. 20-21) afirma que as práticas de conhecimento que criam entidades, categorias, comportamentos, que indicam sensações, ações e emoções como normais, como pertencentes aos padrões morais da normalidade, produzem subjetividades $^{\mathrm{v}}$. Os discursos que os expressam determinam as categorias de pessoas que existem, as que estão incluídas, e aquelas que, distintas dos padrões formulados, não podem existir. É esse efeito circular decorrente da relação entre produção de conhecimento e relações de poder que cria os sujeitos e, além disso, estão sempre associadas às relações de poder da sociedade em questão, formando o híbrido fundamental que Foucault chama de poder/saber. 
Nesse sentido, conforme as discursos variam de acordo com cada contexto histórico, também as formas de subjetividade passíveis de existência variam.

Por outro lado, é possível contestar e transformar essas categorias de identidades, de subjetividades à medida em que as expomos como degradantes construções sociais e não como expressões de fatos naturais. A partir delas a palavra dos excluídos não é ouvida, não é considerada racional e não existe. $\mathrm{O}$ discurso por eles proferido não existe perante as instituições sociais, estas instituições que possuem critérios arbitrários de separação entre os indivíduos, os quais são historicamente modificáveis, de acordo com o contexto social, gerando a exclusão de um grupo específico por meio do exercício de pressão institucional e até mesmo de violência institucional.

Segundo Johanna Oksala (2011, p. 55), para Foucault, a linguagem produz significados independentemente das iniciativas do sujeito, ela não apenas descreve e traduz experiências do sujeito, nem tampouco funciona apenas como um instrumento de narrativa, a linguagem forma a própria realidade. A linguagem é a própria caracterizadora da liberdade, é ela que torna as experiências possíveis, formando um horizonte ilimitado que permite uma variedade de experiências, é a variabilidade de horizontes linguísticos representando experiências imersas em determinada tradição que Gadamer outrora tratou.

A linguagem não deve ser compreendida como um sistema hermético, isolado, que não sofre interferências do meio externo, mas sim dentro de um contexto histórico dos sujeitos que a produzem e interpretam, daqueles que a partir dela formulam discursos. (Martins, 2004, p. 7) A enunciação, assim, é o próprio ato de colocar a linguagem em funcionamento, de transformá-la, de torná-la discurso, o qual é pertencente à esfera individual e subjetiva.

Nesse contexto inserimos a discussão sobre a violência normativa. A violência normativa não é a normatização de certo tipo de violência, não é como a legitimação normativa da violência em si mesmas, mas sim a violência decorrente de determinadas normas, que podem autorizar a violência física propriamente dita, ou praticar outras formas de violência que incidam diretamente sobre a subjetivação dos corpos, sobre a conduta e o comportamento, as opiniões e ações e que, ainda, podem ocultar as violências sofridas rotineiramente pela opressão, pela exclusão (Toneli e Becker, 2010, p. 6).

Segundo Diana Mesquita (2008, p. 63), Foucault aponta a "vontade de verdade" como um dos sistemas de exclusão do discurso e que se caracteriza por ser um tipo de separação historicamente construída" o qual exerce um poder de coerção delimitando o que pode ou não ser dito. A referida autora também alerta que, de acordo com Foucault, precisamos não ficar à mercê das interdições provocadas pelo discurso e que para isso são necessárias três decisões: 
questionar a vontade de verdade, restituir ao discurso seu caráter de acontecimento (com ceticismo em relação aos universais antropológicos) e, por fim, suspender a soberania do significante (retirar a centralidade do humano).

Os discursos, portanto, sempre são produzidos como decorrência de relações de poder, estritamente ligados, não podendo ser dissociados. As sociedades, por sua vez, são frutos de uma construção histórica, marcada por diversas descontinuidades e rupturas nas práticas discursivas, as quais são controladas, selecionadas, organizadas e redistribuídas pelos procedimentos que determinam quais discursos podem ser produzidos e quais não (Mesquita, 2008, p. 65).

A partir dessas práticas discursivas, a normalidade passa a ser o local em que é mantida a possibilidade de governar os corpos, de estabelecer domínio e de moldar subjetividades, considerando os sujeitos a partir dos padrões de normalização, exercendo sobre eles o biopoder, o poder sobre suas vidas (Lunardi, 2001). Logo, a norma, o normal, o normalização são estabelecidos por meio do controle e da regulação não só da população, mas também dos corpos individuais (Lunardi, 2001). "O poder sobre a vida adquire no século XX, no entanto, novos contornos, deixando de ser gerenciado pelo Estado ao transferir-se para a esfera privada ou social, criando biosociabilidades que promovem o agrupamento de indivíduos conforme critérios", aqui surge a biopolítica (Assman et al., 2007, p. 20).

Partindo já de uma relação entre os pensamentos de Foucault e Gadamer acerca do papel da linguagem, adentramos ao encontro de Foucault e Dussel, o qual se dá ao voltarem seus olhos para a situação dos excluídos da sociedade, ao tomarem como ponto de partida para uma ação libertadora da ordem disciplinar. Segundo Clara Borges (2005, p. 50), Foucault acredita que para isso é necessária uma nova teoria do direito voltada "às ínfimas e capilares relações de poder que funcionam no corpo social (entre os súditos), analisando a dominação, as múltiplas sujeições exercidas pelo discurso jurídico, através das práticas judiciárias”. Também de acordo com o referido autor, para Dussel o passo inicial da ação crítica é justamente o desmascaramento dos mecanismos de dominação, mapeando os lugares de resistência, para desenvolver uma prática libertadora.

Desse modo, devemos ter em conta que "a norma não produz o sujeito como seu efeito necessário, tampouco o sujeito é totalmente livre para desprezar a norma que inaugura sua reflexividade" (BUTLER, 2017, p. 31), não há, portanto, um determinismo das normas sobre as subjetividades, mas tampouco há uma total liberdade para o surgimento de novas subjetividades que sejam compreendidas como existentes. Esse sistema de reconhecimento ${ }^{\mathrm{vi}}$ como sujeito existente é, por sua vez, consequência de um regime de verdade em vigor naquele 
contexto, que determina quais são os sujeito de reconhecimento e estabelece as normas para que ele ocorra.

Por essas considerações, entendemos, a partir de Foucault, que as relações de poder não são necessariamente negativas, nem tampouco os seus efeitos. Tais relações podem, por outro lado, ser produtivas, produtivas de comportamentos, de condutas, de padrões morais e éticos e de subjetividades. Para compreender a capacidade de ser reconhecido como um sujeito, o conceito anteriormente apresentado "violência normativa" retira de nosso foco "a idéia de uma violência exercida sobre um sujeito pré-formado para uma violência que se dá "dentro" do processo de formação da subjetividade" (Toneli e Becker, 2010, p. 1). É esta que permite que os sujeitos sejam submetidos à violência rotineira a partir da invisibilidade dela.

Segundo Maria Toneli e Simone Becker (2010, p. 4), Butler entende que o reconhecimento de indivíduos como sujeitos ocorre por meio de "Uma prática reguladora é uma prática normativa que pode aparecer como uma lei, mas, em geral, funciona muito mais a partir da expectativa social, pressão de pares etc". Assim, as categorias identitárias são efeitos das instituições, práticas e discursos e, contingentes. Tais discursos se alternam como discursos verdadeiros, "a temporalidade dos arranjos estratégicos das relações de poder determina a provisoriedade dos procedimentos que gravam o discurso com efeitos de verdade. Há, portanto, uma constante luta das práticas discursivas pela verdade, pela hegemonia de um determinado discurso." (Borges, 2005, p. 47)

Neste sentido, devemos compreender as subjetividades como em permanente processo de formação, à medida que se alteram as relações de saber-poder-verdade, também se alteram os padrões de reconhecimento das subjetividades. Em razão disso, devemos problematizar os binarismos decorrentes dessas relações que determinam os incluídos e os excluídos, os existentes e os não existentes. Para isso devemos romper a capacidade da violência normativa de produzir outras formas de violência, bem como tornar visíveis estas violências ocultadas pela violência normativa. "Trata-se, em última instância (ou primeira?) de 'fazer a vida possível', certamente uma empreitada teórico-política" (Toneli e Becker, 2010, p. 7).

A relevância desta pesquisa, então, está relacionada ao fato de que atualmente as discussões sobre igualdade e justiça giram em torno do binômio exclusão/inclusão, sendo que é por meio das estratégias das relações de poder, tratadas por Foucault, que se define quais grupos participam dessa relação (Nardi et al., 2003, paginação irregular). Segundo André Duarte (2012, p. 28), “o alcance ético-político contemporâneo do conceito foucaultiano de subjetivação diz respeito à invenção de novas formas de vida e novos modos de relação entre 
indivíduos, desde que elas não sejam nem homogêneas nem superponíveis às formas culturais gerais".

A narratividade, portanto, a prática linguística-discursiva é mesmo o modo pelo qual é possível romper com as interdições historicamente produzidas pelas práticas discursivas hegemônicas, é somente pela linguagem que é possível superar as próprias limitações linguísticas, ao adquirir voz, ao empoderar-se, como indivíduo e como membro de um coletivo, é que se adquire participação política, capacidade de reivindicar, de lutar, de resistir às normalizações. Diante do exposto, na seção seguinte iremos discutir e apresentar uma hipótese ética que venha a possibilitar a participação dessas formas de vida heterogêneas em posição de igualdade, tendo em consideração as suas distinções em relação às culturas hegemônicas.

\section{Alteridade como libertação das subjetividades distintas}

Considerando que partimos do histórico do pensamento social hegemônico, e iremos propor uma discussão a partir da prática da libertação, destacamos novamente que essa prática gira em torno de uma discussão sobre dominação, sendo o controle social um pressuposto para a realização desta, diante disto, assevera ser comum atribuir à dominação a face da hegemonia (dominação somada ao controle social), tendo o controle social, por sua vez, uma face de ideologia como forma de modelar os indivíduos da sociedade de acordo com o padrão desejado (Castro, 2015, p. 93), produzindo e normalizando subjetividades.

Percebemos que hoje, um público cada vez mais variado de subjetividades e verdadeiramente multicultural tem reivindicado e obtido atenção para essas culturas e narrativas que tem sido historicamente negligenciadas e ocultadas como inexistentes, o que acarreta a invasão desses espaços de narrativas incontestadas anteriormente ocupadas pelas culturas hegemônicas (Said, 2007, p. 66). Em razão disso, entendemos como necessária a busca por novos parâmetros de desenvolvimento de uma ética comunitária na qual essas subjetividades tenham participação.

Por isso, buscamos no estudo da prática da libertação, o qual é "comprometido com a superação das relações de colonização, colonialismo e colonialidade" (Piza, 2013, p. 91), com a construção de um pensamento fundado na alteridade, por meio do método analético, uma via para o reconhecimento dos povos excluídos como sujeitos de direitos. Para isso, antes de tudo, devemos ter em conta que estes povos, interpelam "eticamente pelo reconhecimento da alteridade absoluta" (Sidekum, 2011, p. 40), desde a sua situação de exterioridade ao sistema mundo vigente, por direitos culturais próprios de sua comunidade. 
A construção desse pensamento de exclusão foi, de forma mais expressiva, oriunda da Modernidade, gerando um pensamento jurídico e político de abstração dos sujeitos como sujeitos de direitos e de não reconhecimento desses sujeitos. As sociedades modernas, portanto, podem ser vistas como sociedades cínicas. O indivíduo cínico afirma o que pensa, não esconde o que quer dizer, expressa o seu discurso de descaso pelas convenções sociais, pela moral vigente e esperada, pelo Ser do Outro, tem desprezo pela existência deste (Piza, 2016, p. 80).

A racionalidade cínica não vê como necessária a manutenção do caráter ético, preza pelo falar franco, ainda que ele implique na supressão, na anulação, no descarte do Outro. No cinismo "o outro é percebido, epistemologicamente percebido; o cínico só não se relaciona com ele, não se compadece, não se afeta, não entra em diálogo, pois não se importa” (Piza, 2016, p. 83). O indivíduo cínico tem conhecimento do sofrimento do Outro, da sua condição de excluído do sistema mundo vigente, mas não assume a responsabilidade ao ser por ele interpelado.

Esse pensamento cínico foi construído a partir de significados eurocêntricos produzidos pela Totalidade - sociedades hegemônicas - ao longo da história e reproduzidos pelos indivíduos pertencentes às sociedades periféricas, assumindo esses significados como próprios, como identificação de si mesmos, ignorando a sua condição histórica distinta. Por meio da reprodução desse pensamento, vê-se o outro que exerce sua individualidade distinta como Outro e ignora-se a sua distinção.

A distinção/diferença é tratada pelos cínicos de forma que a reduzem ao Mesmo. Os indivíduos de uma sociedade cínica, ao se depararem com identidades diferentes, não procuram compreendê-las em sua distinção, não buscam servir ao Outro que interpela demonstrando suas necessidades como Outro, mas sim, as compreendem a partir do Mesmo, somente reconhecidas e respeitadas quando assimiladas de acordo com a identidade europeia generalizada, universalizada, imposta como modelo de sociedade civilizada, racional. Conforme afirma Suzy Piza (2016, p. 83), a contemporaneidade brasileira tem vivenciado este contexto de cinismo da sociedade de forma bastante expressiva nos últimos anos.

Tendo compreendido esse conceito, indicamos como necessário que o Eu integrante da Totalidade se permita ser interpelado pelo Outro, ainda que tenhamos consciência de que ele jamais poderá compreender o Outro em todos seus aspectos - pela sua própria limitação de compreensão e por já partir de sua condição de Mesmo - ele deve se compadecer com as necessidades do outro e tomá-las como verdadeiras. Ou seja, é necessária uma abertura ao Outro, a qual se dá por meio da linguagem, é a possibilidade e a potencialidade da comunicabilidade que permite a expressão e a participação política do Outro em condição de igualdade. 
Dussel (1995, p. 52) entende “como 'interpelação' um enunciado de desempenho sui generis emitido por alguém $(H)$ que, em relação a um ouvinte $(O)$, encontra-se 'fora' ou 'além' (nesse sentido, transcendental) do horizonte ou marca institucional, normativo do "sistema"'. A Filosofia da Libertação parte de uma negação da negação, ou seja, da negação de um sistema que nega a existência do Outro como tal, como exterior. É, então, o momento de empoderar o Outro, pois reconhecendo-o como tal, ele se revigora, adquire força. O objeto da Filosofia da Libertação, na qual fundamentamos este projeto, se trata do reconhecimento da corporalidade que sofre, que interpela suas necessidades desde sua situação marginal no sistema mundo.

Assim, como meio de tornar possível essa abertura ao Outro e retirá-lo da condição de não-ser, Dussel propõe o método analético. O método analético requer um ser intrinsecamente ético, o saber ouvir o Outro. Implica a transcendência, a saída do sistema de Totalidade para a compreensão do Outro que está para além dele, é o assumir um compromisso ético para com o Outro, ter responsabilidade em relação ao desenvolvimento dele como ser distinto.

Por isso, não se trata de apenas reconhecer e tolerar a sua existência, para a ética da libertação, tolerar o Outro que foi vítima de opressão não é "suficiente", é necessário ter solidariedade para com o outro, empatia, considerando sua alteridade. "O saber-ouvir é o momento constitutivo do método [analético] mesmo; é o momento discipular do filosofar; é a condição de possibilidade do saber-interpretar para saber-servir (a erótica, a pedagógica, a política, a teológica)"vii (tradução nossa) (Dussel, 1973, p. 124). O método analético, para Dussel, transcende os limites deste sistema vigente, vai para além, buscando compreender o outro exterior à Totalidade (Dussel, 1995).

Segundo Emmanuel Levinas (1980, p. 23), a palavra "transcendente" significa a exterioridade absoluta da metafísica, está para além do jogo interior de "si a si". Para este mesmo autor, a verdadeira exterioridade é metafísica e, ao invés de figurar como uma carga negativa que pesa sobre o Outro distinto causando a sua exclusão, na verdade, exige-o como Ser livre, capaz de manifestar-se (Levinas, 1980, p. 283).

Em crítica ao comportamento inerte dos indivíduos cínicos perante o sofrimento do Outro, o próprio Dussel afirma não ser suficiente somente a tolerância em relação ao Outro, a indiferença negativa inerente à tolerância é incompatível com as necessidades da vítima que sofre, razão pela qual a ética da libertação exige um comportamento para além da tolerância, um comportamento solidário em substituição ao cínico, um comportamento ativo para servir o outro nas necessidades para que venha a se desenvolver como povo distinto (Dussel, 2006-b, p. 07), responder ao rosto (do Outro), às suas necessidades, significa entender o seu significado, reconhecê-lo ${ }^{\text {viii }}$, despertar para aquilo que é precário em outra vida, ou mesmo para vida em si 
mesma, é um reconhecimento da condição de precariedade, de exclusão do Outro (Butler, 2006, p. 169).

É necessário, portanto, criarmos consciência ética, restabelecendo a relação com o Outro, abrindo-nos à afirmação do seu projeto existencial autêntico, de modo a lhe permitir a livre manifestação, visto que para a América Latina significar-se, por si mesma, como identidade distinta, não inferior, é preciso que passe a identificar-se como Outra, não assumindo para si a identidade do Mesmo que negou sua distinção, ou seja, é mister o desenvolvimento da filosofia da libertação. Esta, por sua vez, se caracteriza por rechaçar o eurocentrismo, por meio da descolonização do ser, do saber e do viver, a partir da análise das vidas negadas, para permitir o desenvolvimento destas.

Este trabalho, portanto, tem como hipótese a desconstrução das instituições presentes no sistema mundo vigente, por meio do empoderamento das subjetividades distintas para que tenham voz, para que possam se expressar por si mesmas linguisticamente no seio da comunidade política em sua situação de alteridade (Clavero, 2014). Para isso, segundo Dussel, para a Filosofia da Libertação não é interessante somente a reforma da sociedade construída pela Totalidade vigente, mas sobretudo a superação libertadora desse modelo de sociedade e das instituições por ele criadas (Dussel, 1992, p. 402).

A tomada de consciência pelo oprimido de sua condição histórica e a sua posterior organização em movimentos sociais que objetivem a libertação resulta em um momento “crítico-criativo", crítico pois não aceita o atual conceito atribuído à noção de direitos humanos voltada à Totalidade e criativo, pois exige uma postura ativa de criação do novo significado.

A transformação desse sistema originariamente excludente se dá pela conscientização dos indivíduos pertencentes à Totalidade da necessidade de incluir o Outro no sistema mundo, em um novo sistema surgido pelo ressignificar dos direitos humanos, para que representem materialmente uma universalidade, sem abandonar a genericidade humana e, também, levando em consideração as particularidades individuais.

Com isso, há a destruição de instituições vigentes - e por destruição não entendemos "ruína, mas desmontar, demolir, pôr de lado [...] significa: abrir nosso ouvido, torná-lo livre para aquilo que na tradição do ser do ente nos inspira" (Heidegger, 2013, p. 27) - por iniciativa de movimentos e manifestações sociais. Os futuros globais, assim, devem ser construídos por opções decoloniais, descolonizando a matriz colonial de poder, pondo fim ao pensamento moderno de superioridade europeia e seus derivados. (Mignolo, 2001, p. 49).

Aníbal Quijano (2002, p. 23) afirma como alternativa não a negação da integração mundial, da pretensão de universalização, mas permitir que o desenvolvimento dessa integração 
se dê de forma mais completa, negando a conflitividade sistemática oriunda das dominações e da violência dela decorrente, permitindo que a diversidade dos povos e seres individualmente considerados deixem de ser um fator gerador da desigualdade - como na questão de raça - e que os indivíduos possam ser social e individualmente livres no seio das relações sociais.

Portanto, sugerimos o pluralismo comunitário-participativo, em observância das práticas dos sujeitos sociais, como forma de redefinir e afirmar a participação políticas das subjetividades distintas historicamente excluídas, numa perspectiva de interculturalidade, comprometido com a alteridade que funcione como projeto contra-hegemônico que atua de forma mais direta no reconhecimento dos sujeitos sociais e de construção de novos poderes institucionais democráticos a partir desta perspectiva do pluralismo (Wolkmer, 2006).

Por fim, ressaltamos que pensar a luta pelo reconhecimento requer que cada uma das partes envolvidas na relação reconheça não só que a outra necessita e merece reconhecimento, mas também que cada uma, em um sentido distinto, se sinta obrigada pela necessidade do Outro, pela mesma demanda por ele expressada (Butler, 2006, p. 71). Como afirma Luiz Carlos de Freitas (2005, p. 107), "Estamos precisando de acolhimento, de solidariedade, de coletivo, de consenso negociado, provisório, mas como construção histórica permanente", para isso, necessitamos de histórias desintoxicadas e sóbrias que demonstrem a multiplicidade e complexidade da história, sem que essa seja vista como uma construção impessoal, ou unitária e universal oriunda das culturas hegemônicas (Said, 2007, p. 171).

\section{Considerações finais}

Tendo feito as discussões que consideramos pertinentes para a temática proposta neste trabalho, partimos a algumas considerações finais, a fim de ratificar ideias centrais necessárias para a composição da hipótese formulada.

Para isso, destacamos que ao discutir as noções de identidade e diferença, para além de dar ênfase à relação direta entre a delimitação das identidades e o surgimentos das diferenças, as quais estão em constante tensão e dela necessitam para a sua manutenção, precisamos também discutir questões mais profundas como a das subjetividades, as quais são definidas como sendo a noção de um indivíduo sobre si mesmo. Essas subjetividades, por sua vez, são constituídas, expressas e representadas por meio da linguagem, ou seja, a linguagem é o meio mesmo de existência da subjetividade.

Diante disso, ao realizar uma análise sobre a possibilidade de formulações linguísticas e da participação em práticas discursivas as quais são indispensáveis para a expressão das 
subjetividades distintas, percebemos, a partir das críticas de Foucault, como historicamente as relações de poder determinantes da produção do saber e das práticas discursivas têm gerado o ocultamento das subjetividades distintas que não se encontram incluídas nos padrões normalizadores hegemônicos, ou seja, aquelas subjetividades não normalizadas são consideradas como inexistentes, não possuem voz, seus discursos são inválidos e ilegítimos. Desse modo, essas mesmas subjetividades se encontram excluídas da participação política na sociedade justamente em razão de não poderem formular as suas próprias narrativas.

Em razão da insustentabilidade em nosso contexto social atual da manutenção da racionalidade cínica como fundamento para o ocultamento das diferenças, para a supressão da voz daqueles que não são assujeitados e normalizados para se adequarem aos padrões hegemônicos, realizamos o esforço de buscar uma alternativa para a proposição da superação da referida racionalidade, a fim de empoderar as subjetividades distintas, para que formulem suas próprias narrativas e discursos que ensejem a sua participação política.

Portanto, formulamos como hipótese a alteridade, a abertura para o Outro, para a diferença, a disposição para além de saber-ouvir a voz do Outro (além da tolerância), também o saber-servir (uma ética da responsabilidade), em que aquele que se encontra incluído nos padrões hegemônicos adote uma postura da ética da solidariedade, da abertura para o Outro distinto, a ser considerado em condição de igualdade. Sugerimos não apenas o reconhecimento, como uma postura de mera liberalidade desse Eu hegemônico, mas uma postura de verdadeira responsabilidade, respeito, igual consideração para viabilizar a autodeterminação do Outro, em seus próprios valores, normas e moralidade.

Destacamos, por fim, que para isso não é suficiente apenas o desenvolvimento dessa nova racionalidade fundada na alteridade, mas sobretudo a ruptura da racionalidade moderna cínica e das instituições que com ela coadunam, para a formulação de novas proposições e criação de outras instituições já conformes a essa racionalidade da alteridade.

\section{Referências}

ARRIZABALAGA, L.G. Hermenéutica del linguaje y simbolismo. UNED, Madrid: ÉNDOXA: Séries Filosóficas, n. 20, 2005.

ASSMAN, S. J.; PICH, S.; GOMES, I. M.; VAZ, A. F. Do poder sobre a vida e do poder da vida: lugares do corpo, biopolítica. Cascavel: Temas \& Matizes, v. 11, n. 6, 2007. Disponível em: http://e-revista.unioeste.br/index.php/temasematizes/article/viewArticle/2500. Acesso em: 9 jul. 2019. 
BILGRAMI, A. Apresentação. In: SAID, E. W. Humanismo e crítica democrática. Rosaura Eichenberg (trad.). São Paulo: Companhia das Letras, 2007.

BITTAR. E. C. B. Reconhecimento e direito à diferença: teoria crítica, diversidade e a cultura dos direitos humanos. p. 551-565. Disponível em

http://www.revistas.usp.br/rfdusp/article/viewFile/67869/70477.

BLEICHER, J. Hermenêutica Contemporânea. Lisboa: Edições 70, 2002.

BORGES, C. M. R. O discurso dos excluídos: o encontro de Dussel e Foucault. Porto Alegre: Revista da Faculdade de Direito da Universidade Federal do Paraná, v. 38, 2005. Disponível em: https://revistas.ufpr.br/direito/article/view/1760/1457. Acesso em 9 jul. 2019.

BRAIDA, C. R. Compreensão hermenêutica e suspeição genealógica. Revista PERI, v. 07, n. 01, p. 1-33, 2015.

BUTLER, J. Quadros de guerra: Quando a vida é passível de luto? Rio de Janeiro: Civilização brasileira. 2015.

BUTLER, J. Relatar a si mesmo: crítica da violência ética. Trad. Rogério Bettoni. 1. ed. Belo Horizonte: Autêntica Editora, 2017.

BUTLER, J. Vida precria: el poder del duelo y la violencia. Tradução de Fermín Rodríguez. Buenos Aires: Paidós, 2006. Disponível em:

https://psicanalisepolitica.files.wordpress.com/2014/10/butler-judith-vida-precaria.pdf. Acesso em: 15 nov. 2018.

CASTRO, L.A. Criminologia da libertação. Rio de Janeiro: Revan: ICC, 2015.

CLAVERO, B. Sujeto sin derechos y enemigo sin garantías en la Declaración Universal de Naciones Unidas, 1945-1966. In: Derecho global: por una historia verosímil de los derechos humanos. Madrid: Editorial Trotta, 2014, cap. 1, p. 21-92.

CORDEIRO, E. Foucault e a existência do discurso. Braga/Portugal: Cadernos do Noroeste, v. 8, 1995. Disponível em: http://www.bocc.ubi.pt/pag/cordeiro-edmundo-foucaultd.pdf. Acesso em: 9 jul. 2019.

DUARTE, A. Singularização e subjetivação: Arendt, Foucault e os novos agentes políticos do presente. Natal: Princípios Revista de Filosofia, v. 19, n. 32, jul/dez/ 2012. Disponível em: https://periodicos.ufrn.br/principios/article/view/7560. Acesso em: 9 jul. 2019.

DUSSELL, E. Desconstrucción del concepto de "tolerancia" (de la intolerancia a la solidariedad), México: UAM-Iz., 2006-b. Disponível em: http://red.pucp.edu.pe/wpcontent/uploads/biblioteca/090508.pdf. Acesso em: 31 ago. 2018.

DUSSEL, E. El metodo analéctico y la filosofía latinoamericana. Nuevo Mundo, Mendoza, t. 3, n. 1, enero/jun. 1973. 
DUSSEL, E. Filosofia da libertação: crítica à ideologia da exclusão. São Paulo: Paulus, 1995.

DUSSEL, E. Filosofía de la liberación: desde la práxis de los oprimidos. Carthaginensia:

Revista de estúdios e investigación, v. 8, n13-14, p. 395-414, 1992. Disponível em: https://dialnet.unirioja.es/servlet/articulo?codigo=227078. Acesso em: 31 ago. 2018.

FIGAL, G. The Doing of the Thing Itself: Gadamer's Hemeneutic Ontology of Language. In: The Cambridge Companion to Gadamer. Cambridge University Press, USA, 2002.

FOUCAULT, M. A ordem do discurso: aula inaugural no Collége de France pronunciada em 2 de dezembro de 1970. Trad. Laura Fraga de Almeida Sampaio. $5^{\text {a }}$ ed. São Paulo: Edições Loyola, 1999.

FREITAS, L. C. Uma pós modernidade de libertação: reconstruindo as esperanças. Campinas, SP: Autores Associados, 2005.

GADAMER, H.G. O problema da consciência histórica. 2. ed. Rio de Janeiro: Editora FGV, 2003.

GADAMER, H. G. Verdade e método I: traços fundamentais de uma hermenêutica filosófica. 15. ed. Petrópolis: Vozes, 2015.

GRONDIN, J. Hermenêutica. São Paulo: Parábola, 2012.

HEIDEGGER, M. Que é isto - A filosofia? : identidade e diferença. 3. ed. Petrópolis, RH: Vozes, São Paulo: Livraria Duas Cidades, 2013.

LEVINAS, E. Totalidade e Infinito. Tradução de José Pinto Ribeiro. Lisboa: Edições 70, 1980. Disponível em: https://pt.scribd.com/doc/127217505/Totalidade-e-Infinito-Levinas. Acesso em: 17 out. 2018.

LUNARDI, M. L. Inclusão/Exclusão: duas faces da mesma moeda. Santa Maria/RS: Revista Cadernos de Educação Especial, n. 18, 2011. Disponível em:

https://periodicos.ufsm.br/educacaoespecial/article/view/5181. Acesso em: 9 jul. 2019.

MANSANO, S.R.V. Sujeito, subjetividade e modos de subjetivação na contemporaneidade. Revista de Psicologia da Unesp, [S.1.], v. 8, n. 2, mar. 2018. Disponível em: http://seer.assis.unesp.br/index.php/psicologia/article/view/946. Acesso em: 9 jul. 2019.

MARTINS, A. C. S. Linguagem, subjetividade e história: a contribuição de Michel Pechêux para a constituição da análise do discurso. Montes Claros: UNIMONTES CIENTÍFICA, v. 6, n. 1, jan./jul., 2004. Disponível em:

http://www.ruc.unimontes.br/index.php/unicientifica/article/view/73. Acesso em: 9 jul. 2019.

MESQUITA, D. P. C. Breves incursões sobre os influxos de Michel Foucault na episteme da análise do discurso. Sergipe: Interdisciplinar Revista de Estudos em Língua e Literatura, v. 6, n. 6, jul./dez. 2008. Disponível em:

https://seer.ufs.br/index.php/interdisciplinar/article/view/1128. Acesso em: 9 jul. 2019. 
MIGNOLO, W.D. La colonialidad: la cara oculta de la modernidad. Cosmópolis: el trasfondo de la Modernidad. Barcelona: Península, 2001.

NARDI, H. C.; SILVEIRA, R. S.; SILVEIRA, S. M. A destruição do corpo e a emergência do sujeito: a subjetivação em Judith Butler. In: $2^{\circ}$ Encontro Mundial dos Estados Gerais de Psicanálise, 2003. Disponível em: https://www.academia.edu/16829267/A_DESTRUI\%C3\%87\%C3\%830_DO_CORPO_E_A_ EMERG\%C3\%8ANCIA DO SUJEITO A SUBJETIVA $\% \mathrm{C} 3 \% 87 \% \mathrm{C} 3 \% 83 \bar{O}$ EM JÜDIT H_BUTLER. Acesso em: 9 jul. 2019.

OKSALA, J. Como ler Foucault. Trad. Maria Luiza X. de A. Borges. Rio de Janeiro: Zahar, 2011.

OLIVÉ, L. Discriminación y pluralismo. México: UNAM, Instituto de Investigaciones Jurídicas: Consejo Nacional para Prevenir la Discriminación: Comisión de Derechos Humanos del Distrito Federal. 2006, p. 81 a 101 Disponível em http://www.conapred.org.mx/userfiles/files/BD-DND-9.pdf. Acesso em: 30 jul. 2019.

PIZA, S. O cinismo como posição subjetiva aética e a práxis da libertação. In: BRAMBILLA, B.B.; PIZA, S. (Org.). Subjetividade $\boldsymbol{e}$ Ética na América Latina ou o cinismo e a potencialidade da práxis da libertação. Nova Petrópolis: Nova Harmonia, 2016, p. 79-102.

QUIJANO, A. Colonialidade, poder, globalização e democracia. Novos Rumos, a. 17, n. 37 , 2002, p. 4-28. Disponível em:

http://www.educadores.diaadia.pr.gov.br/arquivos/File/2010/veiculos_de_comunicacao/NOR/ NOR0237/NOR0237_02.PDF. Acesso em: 14 nov. 2018.

RIPANTI, G. Emmanuel Levinas e o infinito diálogo. (Introdução). In: LEVINAS, E. Violência do rosto. Fernando Soares Moreiras (trad.). São Paulo: Edições Loyola, 2014.

SAID, E. W. Humanismo e crítica democrática. Rosaura Eichenberg (trad.). São Paulo: Companhia das Letras, 2007.

SCOTT, J. O enigma da igualdade. Estudos Feministas, Florianópolis, 13(1): 216, jan.abr./2005, p. 11 a 30. Disponível em: http://www.scielo.br/pdf/ref/v13n1/a02v13n1.pdf. Acesso em: 30 jul. 2019.

SIDEKUM, A. Direitos fundamentais: a dignidade humana. Nova Petrópolis: Nova Harmonia, 2011.

TONELI, M. J. F.; BECKER, S. A violência normativa e os processos de subjetivação: contribuições para o debate a partir de Judith Butler. Anais Seminário Internacional Fazendo Gênero: Diásporas, Diversidades, Deslocamentos, Florianópolis, SC, Brasil, 9, 2010. Disponível em:

http://www.fazendogenero.ufsc.br/9/resources/anais/1278169629_ARQUIVO_Trabalhocomp letoMJFTeSBAviolencianormativa.pdf. Acesso em: 9 jul. 2019. 
WOLKMER, A.C. Pluralismo jurídico, direitos humanos e interculturalidade. Revista Sequência, n. 53, p. 113-1128, dez. 2006. Disponível em:

https://periodicos.ufsc.br/index.php/sequencia/article/view/15095. Acesso em: 12 set. 2018.

WOODWARD, K. Identidade e diferença: uma introdução teórica e conceitual. In: SILVA, T.T. (org.). Identidade e diferença: a perspectiva dos Estudos Culturais. 15. ed. Petrópolis, RJ: Vozes, 2014.

Data de recebimento: 03.04.2021

Data de aprovação: 29.07.2021

\footnotetext{
i Para Emmanuel Levinas, o diálogo é um pensamento des-igual, que pensa para além daquilo que está dado, só havendo autêntico diálogo não só pela proximidade, mas também pela absoluta alteridade ou transcendência do Tu diante do Eu, sendo que o verdadeiro acesso à alteridade do outro só é possível quando eu o trato como tu e, antes de falar dele, eu falo a ele (Ripanti, 2014, p. 10).
}

ii No texto original: The horizon is a limited openness, therefore, which changes as soon as one changes one's vantage point. A horizon of meaning, which is a continually changing range of linguistic existence, is a whole insofar as it can give itself together with the infinity of the unsaid.

iii No texto original: "el lenguaje en la concepción gadameriana, no se limita sólo a referir otra cosa: invita a demorarse en él. No está escindido de lo que representa, sino que participa de algún modo en ello".

iv Akeel Bilgrami (2007, p. 13) afirma que a crítica, por sua vez, "consistem em duas coisas aparentemente incoerentes: é filologia, a 'história' das palavras, a 'recepção' de uma tradição, $e$, ao mesmo tempo, é uma 'resistência' a essa tradição e ao repositório de costumes que as palavras acumulam".

${ }^{v}$ Destacamos que o conceito de subjetividade adotado neste trabalho é o que a compreende não como a posse de um estado permanente, mas uma produção incessante a partir de encontros com o outro. Esse outro, por sua vez, não se reduz apenas a outro sujeito, mas também abrange a natureza, os acontecimentos, as invenções, os fatores externos histórico-sociais que produzem efeitos sobre os corpos e sobre as formas de vida. (Mansano, 2009, p. 111).

${ }^{\text {vi }}$ Butler (2015 , p. 20) define o reconhecimento como uma prática recíproca empreendida por pelo menos dois sujeitos, realizada conforme as condições gerais para o reconhecimento socialmente definidas.

vii Texto original: "El saber-oir es el momento constitutivo del método mismo; es el momento discipular del filosofar; es la condición de posibilidad del saber-interpretar para saber-sevir (la erótica, la pedagógica, la política, la teológica)."

viii Charles Taylor (1993) afirma que o reconhecimento devido do Outro não é só uma forma de respeito a ele, mas também uma necessidade humana vital, visto que a falta de reconhecimento pode causar dano a um povo, constituída como uma forma de opressão, fazendo com que ele veja a sua própria identidade como deformada, falsa ou reduzida, inferior. 